Br J Ophthalmol 2006;90:1073-1074. doi: 10.1136/bjo.2006.098897

Correspondence to: Catherine A McCarty, PhD, $\mathrm{MPH}$, Marshfield Clinic Research Foundation, Center for Human Genetics, 1000 North Oak Avenue (ML1), Marshfield, WI 54449, USA; mccarty.catherine@mcrf.mfldclin.edu

\section{REFERENCES}

1 Xu L, Li Y, Zheng Y, et al. Associated factors for age-related maculopathy in the adult population in China. The Beijing Eye Study. Br J Ophthalmol 2006:90:1087-90.

2 Pang CP, Baum L, Chan WM, et al. The apolipoprotein $\mathrm{E}$ epsilon 4 allele is unlikely to be a major risk factor of age-related macular degeneration in Chinese. Ophthalmologica 2000;214:289-91.

3 Schmidt S, Klaver CCW, Saunders AM, et al. A pooled case-control study of the apolipoprotein $E$ (APOE) gene in age-related maculopathy. Ophthalmic Genet 2002;23:209-23.

4 loannidis JPA, Ntzani EE, Trikalinos TA. 'Racial' differences in genetics effects for complex diseases. Nat Genet 2004;36:1312-18.

5 Gold B, Merriam JE, Zernant J, et al. Variation in factor B (BF) and complement component 2 (C2) genes is associated with age-related macular degeneration. Nat Genet 2006;38:458-62.

6 Klein R, Peto T, Bird A, et al. The epidemiology of age-related macular degeneration. Am J Ophthalmol 2004; 137:486-95.

7 Seddon JM, Cote J, Page WF, et al. The US twin study of age related macular degeneration. Relative roles of genetic and environmental influences. Arch Ophthalmol 2005; 123:321-7.
8 Wilson GA, Field AP, Wilson N. Smoke gets in your eyes: smoking and visual impairment in New Zealand. NZ Med J 2001;114:471-4.

9 Evans JR, Fletcher AE, Wormald RPL. 28000 Cases of age related macular degeneration causing visual loss in people aged 75 years and above in the United Kingdom, may be attributable to smoking. $\mathrm{Br} J$ Ophthalmol 2005:89:550-3.

10 Thornton J, Edwards R, Mitchell P, et al. Smoking and age-related macular degeneration: a review of association. Eye 2005;19:935-44.

11 Schmidt S, Haines JL, Postel EA, et al. Joint effects of smoking history and APOE genotypes in agerelated macular degeneration. Mol Vis 2005; 11:941-9.

12 Schmidt S, Hauser MA, Scott WK, et al. Cigarette smoking strongly modifies the association of LOC38771 nd age-related macular degeneration. Am J Hum Genet 2006;78:852-64.

\title{
Chicken and egg
}

\section{J Sloper}

\section{Implications for our understanding of the mechanisms of early development of the visual pathway}

O ur high resolution, three dimensional view of the world depends on the presence of foveas to give high acuity, on an optic chiasm to direct information from the corresponding areas of nasal and temporal retina to the same hemisphere and on the alignment of the visual axes to allow corresponding features in the image from each eye to be aligned and combined into a single stereoscopic percept. Coordinating the development of these different components into an integrated binocular visual system poses a considerable challenge and it is not surprising that defects arise from time to time.

The most common genetic condition to affect chiasmal development is albinism, in which the fovea is hypoplastic and the fundus is hypopigmented. There is misrouting of retinal ganglion cell axons at the optic chiasm and binocular function is reduced or absent. It has generally been assumed that the foveal hypoplasia and excessive crossing of retinal axons at the optic chiasm resulted from deficient synthesis of melanin, although the mechanisms involved have not been determined. ${ }^{1}$ In this issue of BJO (p 1098) van Genderen et $a^{2}$ describe three patients with foveal hypoplasia and electrophysiological findings typical of the chiasmal misrouting found in albinism, but with normal fundal pigmentation. Two were sisters who had been considered to have congenital idiopathic oculomotor nystagmus, while the third had been diagnosed with Kartagener syndrome (primary ciliary dysgenesis and situs inversus) with nystagmus. The observation that foveal hypoplasia and chiasmal misrouting can occur in the presence of normal pigmentation is of considerable interest.

Firstly, these findings confirm that foveal hypoplasia can occur in the absence of hypopigmentation. This has also been described in aniridia, ${ }^{3}$ but those patients did not show electrophysiological evidence of chiasmal misrouting, demonstrating that normal chiasmal development can occur in the presence of foveal hypoplasia. Van Genderen et al suggest that rather than foveal hypoplasia causing chiasmal misrouting, as is generally thought, the relation may be the other way round, with chiasmal misrouting interfering with foveal development. This has substantial implications for our understanding of the mechanisms of early development of the visual pathway. It would imply, for example, that the primary defect in their patients, and also in albinism, is in axonal misrouting at the optic chiasm, with the foveal hypoplasia being secondary to this. In contrast, in aniridia the failure would be in a retrograde signalling mechanism from ganglion cell axons and their central targets to the retina in the presence of a normal chiasm. It is interesting in this respect that the pattern of abnormality of retinal vasculature is different in albinism and aniridia. $^{3}$ Retinal blood vessels are excluded from the foveal region during normal development ${ }^{4}$ so this difference in vasculature could indicate differences in the mechanism of foveal hypoplasia in these two conditions. However the distribution of retinal vessels in the patients described by van Genderen et al was also different from that in albinism.

\section{Rather than foveal hypoplasia caus-} ing chiasmal misrouting, as is generally thought, the relation may be the other way round

Against this retrograde hypothesis is the observation that patients with incomplete congenital stationary night blindness show a degree of visually evoked potential (VEP) asymmetry indicating chiasmal misrouting, but of a lesser degree than is typical in albinism. They do not have foveal hypoplasia. ${ }^{5}$ Also Dorey et al reported three subjects being investigated for albinism, who showed VEP evidence of misrouting, but did not have clinical foveal hypoplasia. ${ }^{6}$ It is possible that lesser degrees of misrouting allow enough axons to acquire synaptic targets to permit foveal development. Alternatively it may be that some other primary defect can cause both foveal hypoplasia and chiasmal misrouting, but not necessarily together.

Both the sequence of normal development and evolutionary data may be of relevance. The first clear signs of nonuniformity of the posterior pole during development are the appearance of a central thickening of the ganglion cell layer and migration of photoreceptors, both of which have been described at 22 weeks of gestation in humans. ${ }^{7}$ As van Genderen et al note, this is well after chiasmal development is complete. 
Retrograde mechanisms are well recognised in neural development, with neurons which do not acquire synaptic targets undergoing degeneration. Retrograde transneuronal degeneration of retinal ganglion cells occurs following visual cortical ablation in young primates. ${ }^{8}$ In the anencephalic human retinal ganglion cells also undergo presumed retrograde degeneration, and there are severe abnormalities of foveal development with no sign of a foveal pit. ${ }^{9}$ Development of characteristic foveal specialisations occurs as early in the retinal ganglion cell layer as in the photoreceptor layer. A mechanism based on chiasmal misrouting causing changes in the acquisition by retinal ganglion cells of central synaptic targets in the lateral geniculate nucleus, with a subsequent failure of retrograde signalling interfering with retinal cell migration, is certainly plausible. Abnormalities of the anatomy of the lateral geniculate nucleus, the synaptic target of retinal ganglion cells, are well described in albino primates. ${ }^{1011}$

In mammalian evolution the presence and enlargement of an uncrossed pathway at the optic chiasm and the development and progressive enlargement of the binocular visual field precede the development of a true fovea. For example, cats have only an area centralis, but have well established binocular visual function and a binocular field of approximately $45^{\circ}$. Development of a true fovea is virtually confined to primates. Thus the mechanisms for chiasmal axonal segregation would appear to have developed earlier than those for foveal specialisation. In this respect it is of interest that the mechanisms which determine axonal guidance at the chiasm appear to differ between humans and mouse, indicating the presence of more than one developmental strategy in mammals. ${ }^{12}$

The above findings may have implications not only for foveal development itself, but also for the position in the fundus at which the fovea develops. The vertical meridian is defined by the position of the fovea at the posterior pole because this is the normal determinant of fixation. Retinal ganglion cells nasal to the fovea normally project to the contralateral hemisphere, while temporal cells project to the ipsilateral hemisphere, with a small band of overlap of ganglion cells along the vertical meridian of the retina. If foveal development is determined by retrograde influences, do these also affect the position at which the fovea develops? In other words, is the vertical meridian determined primarily by the decussation of ganglion cell axons at the chiasm, with the fovea then developing at the vertical midline as defined by the routing of ganglion cell axons at the optic chiasm rather than foveal development defining the vertical meridian, with chiasmal development following? There is substantial variation in the position of the fovea in relation to the anatomical centre of the posterior pole of the eye so that the visual and anatomical axes do not usually coincide. This is seen clinically as variation in angle kappa and in some instances the anatomical misalignment may be sufficient to be mistaken for a small angle squint.

The findings of van Genderen et al raise two immediate questions.

Firstly, is the coexistence of chiasmal misrouting and foveal hypoplasia with Kartagener syndrome fortuitous? Ophthalmological abnormalities are not a recognised feature of this condition, so the association may be coincidental. The authors were unable to find a gene implicated in both conditions, but it is possible that the affected genes occupy adjacent regions as suggested by the authors. However Kartagener syndrome may be easily missed and chiasmal misrouting is only reliably detected by specialised VEP techniques, including multichannel recording, and so may also be missed. Secondly, are there other conditions with either foveal hypoplasia or chiasmal misrouting alone? Both these questions are potentially answerable by clinicians.
This study by van Genderen et al demonstrates how careful study of a rare clinical condition by alert clinicians can throw important light on fundamental developmental mechanisms. It is important that clinicians continue to have the time and freedom to investigate such interesting patients.

Br J Ophthalmol 2006;90:1074-1075. doi: 10.1136/bjo.2006.097618

Correspondence to: John Sloper, Strabismus and Paediatric Service, Moorfields Eye Hospital, City Road, London ECIV 2PD, UK; john.sloper@dial.pipex.com

\section{REFERENCES}

1 Jeffery G. The albino retina: an abnormality that provides insight into normal retinal development. Trends Neurosci 1997; 20:165-9.

2 Van Genderen MM, Reimslag FCC, Schuil J, et al. Chiasmal misrouting and foveal hypoplasia without albinism. Br J Ophthalmol 2006:90:1098-1102.

3 Neveu MM, Holder GE, Sloper JJ, et al. Optic chiasm formation in humans is independent of foveal development. Eur J Neurosci 2005;22: 1825-9.

4 Provis JM, Sandercoe T, Hendrickson AE. Astrocytes and blood vessels define the foveal rim during primate retinal development. Invest Ophthalmol Vis Sci 2000;41:2827-36.

5 Tremblay F, De Becker I, Cheung C, et al. Visual evoked potentials with crossed asymmetry in incomplete congenital stationary night blindness. Invest Ophthalmol Vis Sci 1996:37:1783-92.

6 Dorey SE, Neveu MM, Burton LC, et al. The clinical features of albinism and their correlation with visual evoked potentials. Br J Ophthalmol 2003;87:767-72.

7 Hendrickson AE, Yuodelis C. The morphological development of the human fovea. Ophthalmology 1984;91:603-12

8 Herbin $M$, Boire $D$, Theoret $H$, et al. Transneuronal degeneration of retinal ganglion cells in early hemispherectomized monkeys. Neuroreport 1999:10:447-52.

9 Hendrickson AE, DP, HD. Human retinal development in the absence of ganglion cells. Invest Ophthalmol Vis Sci. 2005;46: E-Abstract 563).

10 Guillery RW, Hickey TL, Kaas JH, et al. Abnormal central visual pathways in the brain of an albino green monkey (Cercopithecus aethiops). J Comp Neurol 1984;226: 165-83.

11 Gross KJ, Hickey TL. Abnormal laminar patterns in the lateral geniculate nucleus of an albino monkey. Brain Res 1980;190:231-7.

12 Neveu MM, Holder GE, Ragge N, et al. Early midline interactions are not important in mouse optic chiasm formation but are not critical in man: a significant distinction between man and mouse. Eur J Neurosci 2006;(in press). 